E International

\title{
Infrastructure for Commercial Vehicle Safety
}

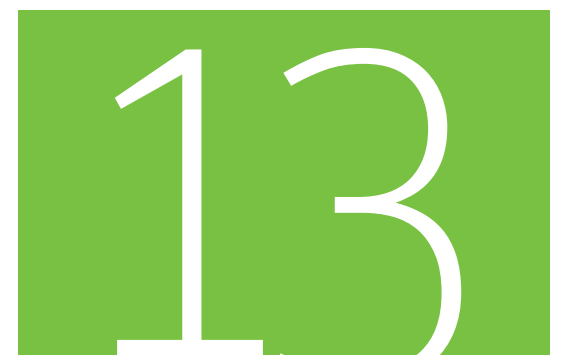

Discussion Paper 2017•13

Christopher M. Poe, Ph.D., P.E.

Texas A\&M Transportation Institute, Dallas, Texas 


\title{
F International Transport Forum
}

\section{Infrastructure for Commercial Vehicle Safety}

Discussion Paper 2017-13

\author{
Prepared for the Roundtable on \\ Commercial Vehicle On-Board Safety Systems \\ January 5-6, 2017, Washington, DC \\ Christopher M. Poe, Ph.D., P.E. \\ Texas A\&M Transportation Institute, Dallas, Texas, USA
}

August 2017 


\section{The International Transport Forum}

The International Transport Forum is an intergovernmental organisation with 59 member countries. It acts as a think tank for transport policy and organises the Annual Summit of transport ministers. ITF is the only global body that covers all transport modes. The ITF is politically autonomous and administratively integrated with the OECD.

The ITF works for transport policies that improve peoples' lives. Our mission is to foster a deeper understanding of the role of transport in economic growth, environmental sustainability and social inclusion and to raise the public profile of transport policy.

The ITF organises global dialogue for better transport. We act as a platform for discussion and prenegotiation of policy issues across all transport modes. We analyse trends, share knowledge and promote exchange among transport decision-makers and civil society. The ITF's Annual Summit is the world's largest gathering of transport ministers and the leading global platform for dialogue on transport policy.

The Members of the Forum are: Albania, Armenia, Argentina, Australia, Austria, Azerbaijan, Belarus, Belgium, Bosnia and Herzegovina, Bulgaria, Canada, Chile, China (People's Republic of), Croatia, Czech Republic, Denmark, Estonia, Finland, France, Former Yugoslav Republic of Macedonia, Georgia, Germany, Greece, Hungary, Iceland, India, Ireland, Israel, Italy, Japan, Kazakhstan, Korea, Latvia, Liechtenstein, Lithuania, Luxembourg, Malta, Mexico, Republic of Moldova, Montenegro, Morocco, the Netherlands, New Zealand, Norway, Poland, Portugal, Romania, Russian Federation, Serbia, Slovak Republic, Slovenia, Spain, Sweden, Switzerland, Turkey, Ukraine, the United Arab Emirates, the United Kingdom and the United States.

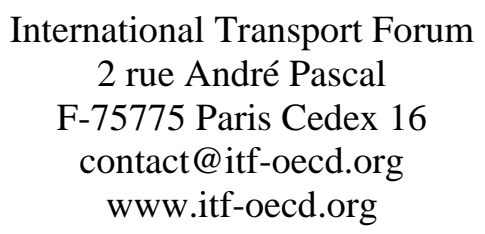

\section{ITF Discussion Papers}

ITF Discussion Papers make economic research, commissioned or carried out in-house at ITF, available to researchers and practitioners. They describe preliminary results or research in progress by the author(s) and are published to stimulate discussion on a broad range of issues on which the ITF works. Any findings, interpretations and conclusions expressed herein are those of the authors and do not necessarily reflect the views of the International Transport Forum or the OECD. Neither the OECD, ITF nor the authors guarantee the accuracy of any data or other information contained in this publication and accept no responsibility whatsoever for any consequence of their use. This document and any map included herein are without prejudice to the status of or sovereignty over any territory, to the delimitation of international frontiers and boundaries and to the name of any territory, city or area. Comments on Discussion Papers are welcome. 


\section{Acknowledgements}

The author is grateful to the Texas A\&M Transportation Institute (TTI) for the time off to prepare this white paper and associated presentation for the International Transport Form Roundtable on Commercial On-Board Safety Systems. The author would also like to thank Mr. Curtis Morgan and Mr. Rajat Rajbhandari from TTI, Dr. Alison Conway of City College of New York, and Mr. Tom Alkim from Rijkswaterstaat for proving content and references to material to support this paper. And lastly, the author would like to acknowledge Dr. Peter Sweatman from CAVita and Mr. Tom Voege from ITF for their guidance before and after the Roundtable. 


\begin{abstract}
While there is increasing information on commercial motor vehicle (CMV) safety systems, truck automation, and truck platooning, there is less information on how roadway and infrastructure technology can improve truck safety, mobility, and efficiency using these technologies. Intelligent Transportation System (ITS), connected vehicle, and vehicle automation technologies are examined to identify safety and mobility applications that can leverage greater integration with infrastructure. Greater connectivity between commercial vehicles and the infrastructure has the potential to reduce crashes, increase productivity, and reduce fuel consumption and emissions. Connectivity holds immediate opportunity to expand traditional ITS solutions for safety and mobility by creating more effective applications that integrate infrastructure data directly with CMVs. This paper serves to facilitate the discussion on how the infrastructure can play a role in the technological advancements being made in the freight and CMV industry.
\end{abstract}




\section{Table of contents}

Introduction ................................................................................................................................. 7

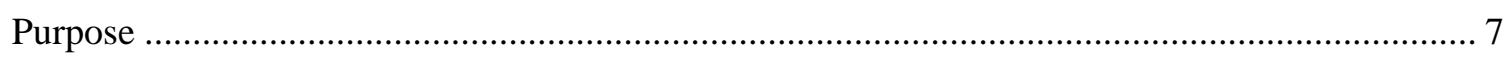

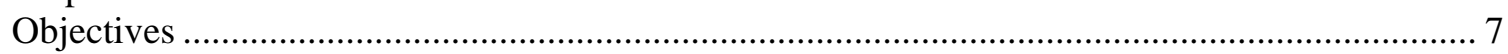

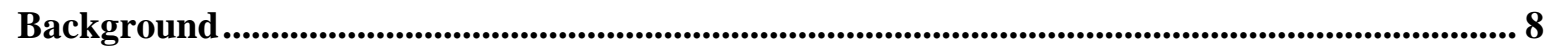

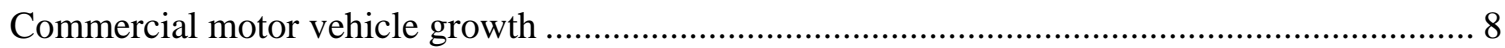

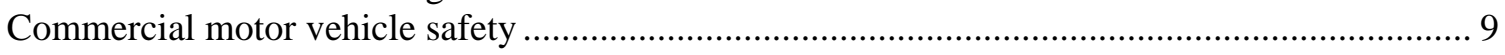

Intelligent Transportation System technologies .......................................................................................... 10

ITS applications to assist commercial motor vehicle safety and mobility .................................. 11

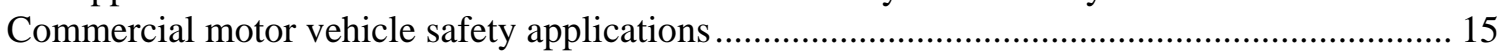

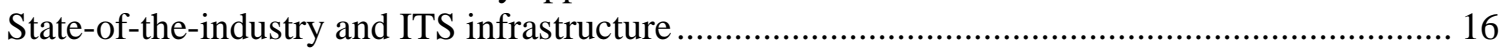

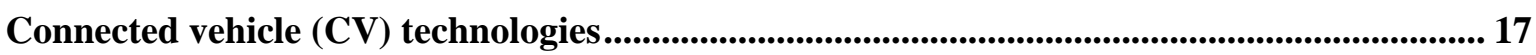

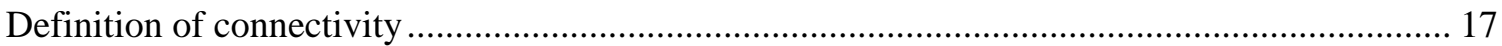

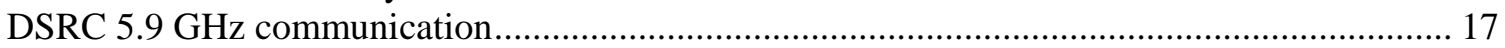

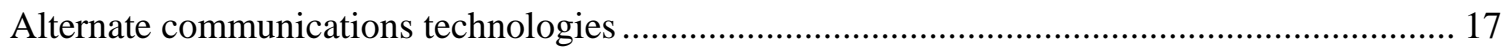

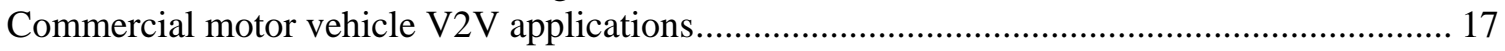

Commercial motor vehicle V2I applications ........................................................................ 18

Infrastructure applications to support commercial motor vehicle safety and mobility........... 19

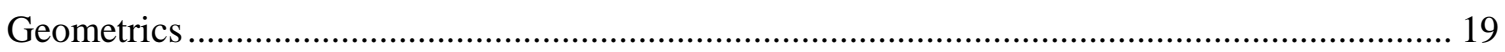

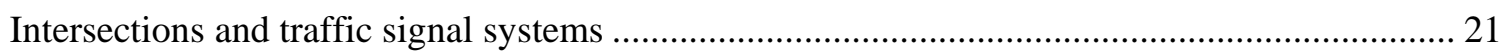

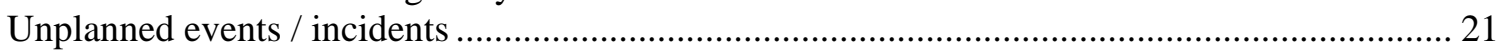

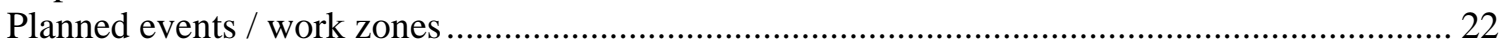

Use of automation on motorways......................................................................................................... 22

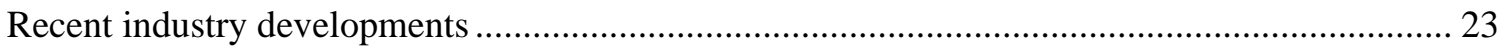

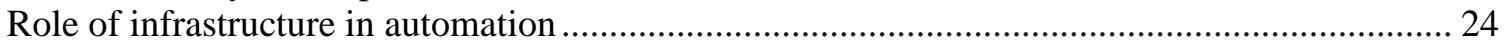

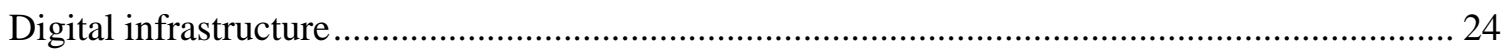

Mixed traffic versus exclusive facilities for automation on motorways ....................................... 24

New opportunities with transformational technologies ................................................................ 25

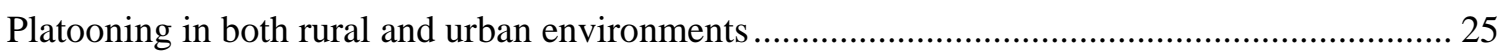

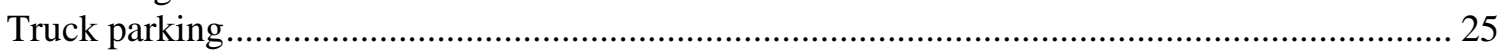

Accommodation of deliveries and last-mile freight movements ............................................... 26

Assessment of near-term and mid-term developments ...................................................................... 26

Summary and observations .................................................................................................................. 27

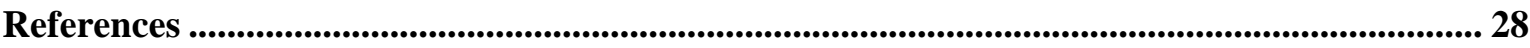


Christopher Poe, Ph.D., P.E., - Infrastructure for Commercial Vehicle Safety

\section{Figures}

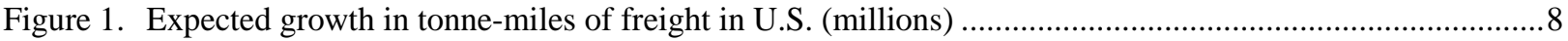

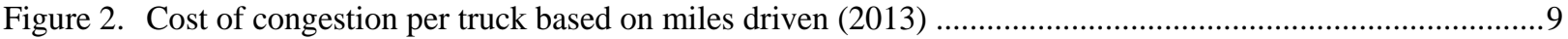

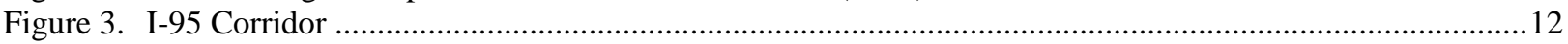

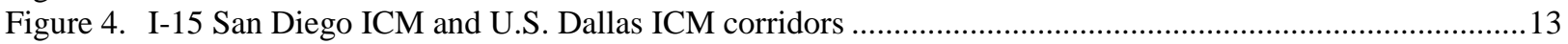

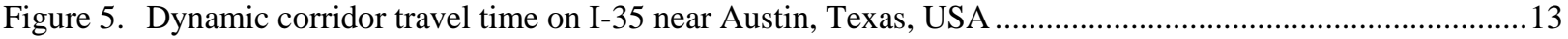

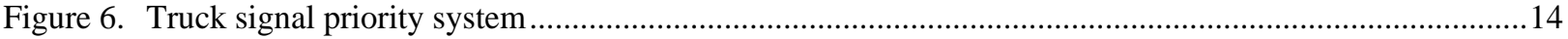

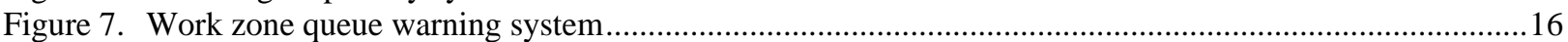

\section{Tables}

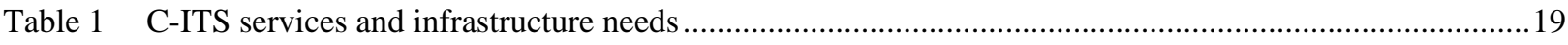

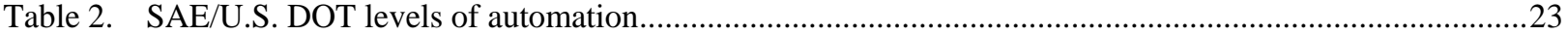




\section{Introduction}

\section{Purpose}

The automotive industry is going through a period of rapid change. As articulated by General Motors Chief Operating Officer Mary Barra, "I believe the auto industry will change more in the next five to 10 years than it has in the last 50 ..." (Barra, 2016). This rapid change is impacting commercial motor vehicles (CMVs) as well. In the U.S., CMVs are defined as a vehicle with a gross combination weight rating over 10,000 pounds, designed to transport more than 15 passengers (including the driver), or is transporting hazardous materials. Much of the technology that is being researched, developed, tested, and deployed has application to both light-duty vehicles and heavy-duty vehicles. At the same time, the intelligent transportation system (ITS) technologies and infrastructure technologies are advancing and creating new opportunities for safety and mobility applications for all vehicles.

The International Transport Forum's (ITF) Roundtable on "Commercial Vehicle On-Board Safety Systems" created a forum to take an in-depth look at the transportation system comprised of vehicles, drivers, and infrastructure. Four papers were commissioned to support the Roundtable.

\section{Objectives}

This paper is one of the four commissioned papers for the ITF Roundtable. The objective of this paper is to look at the developments in ITS technology, vehicle technology, and smart infrastructure that will improve the safety and efficiency of the increasing volume of CMVs. This paper identifies the commercial vehicle industries needs that may be solved by many of these technologies. It also examines the ITS, connected vehicle (CV), and automated vehicle (AV) technologies emerging for safety and mobility applications to address CMV needs.

While there is increasing information on CMV safety systems, truck automation, and truck platooning, there is less information on how roadway and infrastructure technology can improved transportation safety and mobility. ITS technologies collect data on the condition of the infrastructure. Emerging telecommunication technologies offer new methods of transferring infrastructure data to vehicles. This paper serves to facilitate discussion on how the transportation infrastructure and associated data can, and will, play a role in the technological advancements being made in the freight and CMV industry. 


\section{Background}

Technology should be purpose-driven in its deployment. That is, technology should be used to solve a problem or serve a need. This section looks at the CMV industry trends, for growth, safety, and mobility as well as some of the challenges facing the freight industry.

\section{Commercial motor vehicle growth}

Transportation is about the movement of people and good. Freight goods movement has shown steady growth and is projected to continue. Freight in the U.S. is moved by air, rail, truck, water, and pipelines, with the highest share by truck. Truck freight movement can be measured by tonnage and value. Trucks move about two-thirds of the total freight in the U.S., $69.6 \%$ by tonnage and $63.6 \%$ by value (U.S. DOT, 2015). The U.S. DOT has a draft National Freight Strategic Plan out for public comment. In that document, they project the growth in freight by mode through 2040. As shown in Figure 1, overall freight movements are expected to grow more than $40 \%$ by 2040 , with truck freight have the largest growth.

Figure 1. Expected growth in tonnes-miles of freight in U.S. (millions)

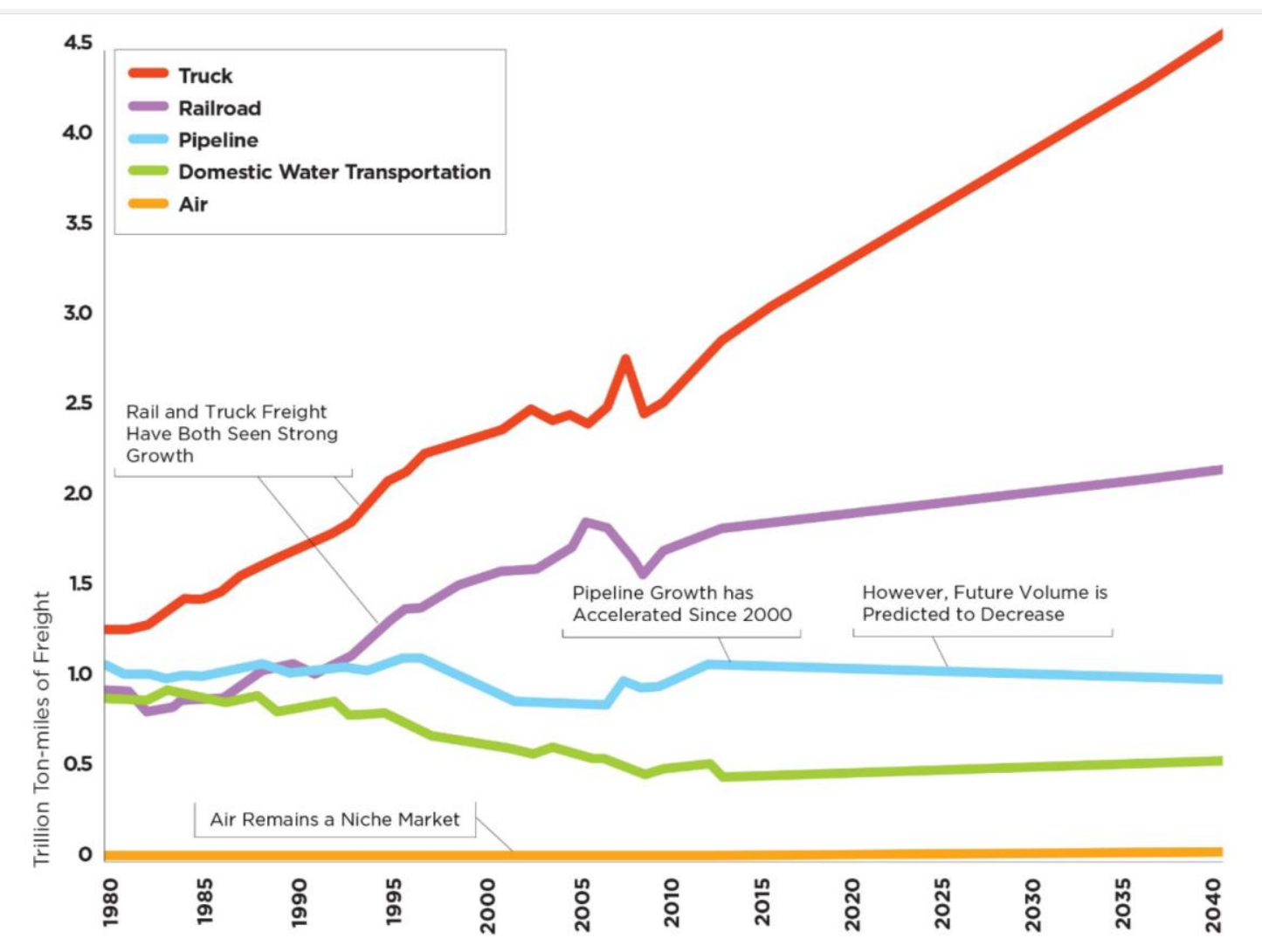

Source: National Freight Strategic Plan (U.S. DOT, 2015).

Similarly, in the European Union (EU), the inland transport of good for the 27 countries that make up the EU-27 move over two-thirds of goods by road [truck], 72.7\% (ERF 2012). The freight transport 
by road has grown by $35 \%$ over the 15 -year period between 1995 and 2010, and has gain a bigger share of the freight distribution by mode. Countries will face challenges in the CMV industry and transportation infrastructure to keep up with this projected growth.

\section{Commercial motor vehicle safety}

Safety is an on-going concern for the CMV industry. In 2014, there were a total of 29989 fatal crashes on the U.S.'s roadways; of which, 3649 (12.2\%) involved at least one large truck or bus. In addition, there were an estimated 6035000 nonfatal crashes; of which, $472000(7.8 \%)$ involved at least one large truck or bus (FMCSA, 2016).

NHTSA examined the 2013 traffic data for large trucks in the U.S. In that year, there were 269294302 total registered vehicles, 4\% of these vehicles were large trucks (defined as a vehicle over 10,000 lbs. gross weight) (NHTSA, 2015). Because large trucks are driven more and operate over longer time periods each day, they make up $9 \%$ of the vehicle miles driven.

In 2013, $12 \%$ of all the motor vehicle traffic fatalities (3964 fatalities) involved large trucks. Of these large truck fatalities, $71 \%$ were occupants of other vehicles, $17 \%$ were occupants of large trucks, and $11 \%$ were non-occupants. Additionally, nearly three-fourths $(73 \%)$ of the large trucks involved in fatal crashes in 2013 collided with other motor vehicles in transport. Thus, large trucks have a significant impact on other vehicles on the roadways, both in terms of the fatalities of occupants in other vehicles and the number of crashes involving other vehicles.

With the projected growth in truck freight movements, the CMV industry will face challenges to reduce the frequency of crashes, reduce the severity of large truck crashes with other roadway users, and continue to reduce the crash rates per vehicle miles or kilometers of travel.

\section{Commercial vehicle mobility/congestion}

The American Transportation Research Institute (ATRI) estimates congestion adds an additional USD 9.2 billion in operation costs for CMVs in the U.S. At the same time, CMV operators lose 141 million hours of productivity due to being stuck in congestion (ATRI, 2013). As shown in Figure 2, that can be a significant cost to the average truck based on the number of miles driven.

Figure 2. Cost of congestion per truck based on miles driven (2013)

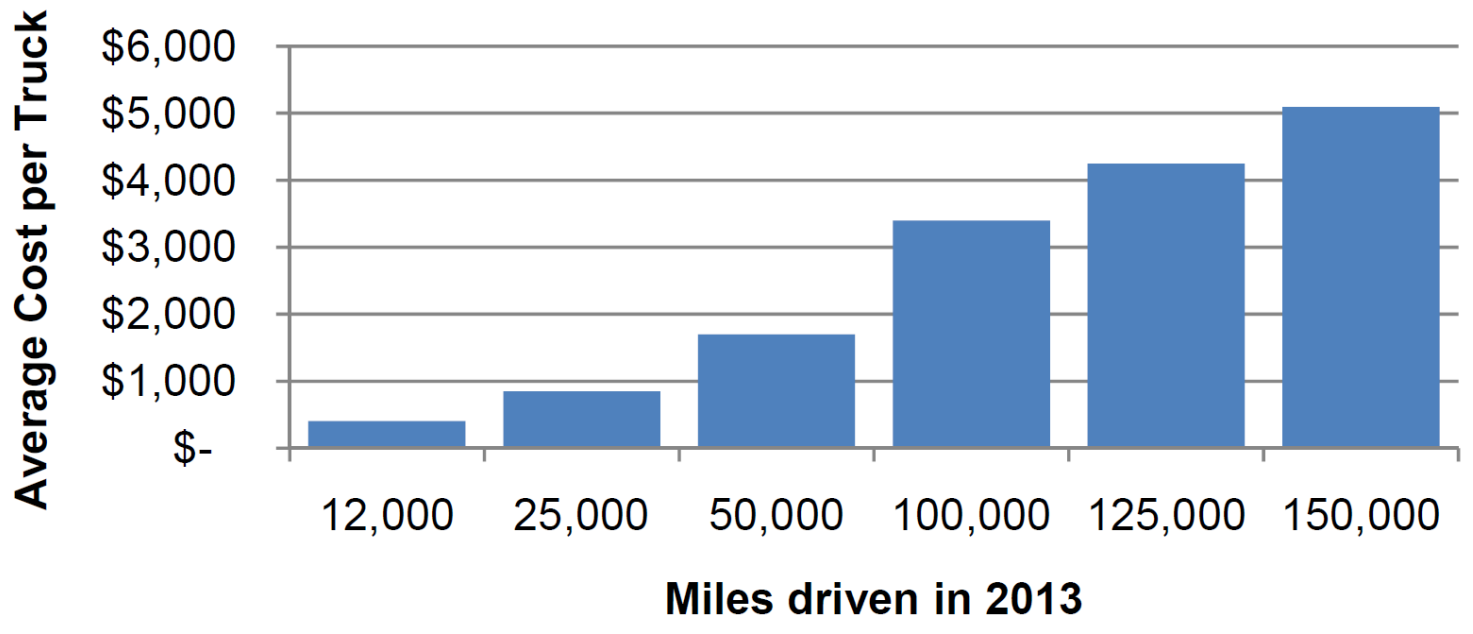

Source: ATRI (2013). 
The cost of congestion in due in part to the infrastructure bottlenecks that constrain roadway capacity. With only modest growth of infrastructure capacity in recent years, especially compared to the growth in vehicle miles of travel, the CMV industry will face challenges of increased congestion costs due to growth in congestion at these bottlenecks.

\section{Operating environments}

CMVs must operating in both urban and rural environments. Each of these environments has challenges to the safety and efficiency of CMV operation. Rural environments tend to represent the longhaul operation between distribution centres. These roadways tend to be high-speed, controlled-access facilities that represent relatively low levels of complexity for freight operations. Alternatively, the urban environments tend to represent the distribution operation from the distribution centres to end businesses and consumers. The roadways in these environment are lower-speed facilities with varying geometry, access, and traffic control and represent much higher complexity for freight operations.

One of the freight logistics issues that is challenging in urban environments is the 'last mile' problem. The last mile refers to the last leg of the supply chain between a distribution center and the customer. The U.S. DOT's National Freight Advisory Committee (NFAC) identified freight operations that minimize community impacts, improve environmental and safety conditions, and support economic productivity and efficiency as a high priority area (NFAC, 2014).

The last mile issue proposes several challenges. In urban areas, traffic congestion hinders delivery times. As trucks move from inter-city, controlled access roadways and onto city streets, the roadway geometry can become more restrictive and impede truck operation and movements. In developed countries, truck operations face growth in the urban regions that may increase delivery distances and times, In developing countries, the lack of infrastructure or quality of infrastructure may impact truck delivery time and cost, thus impacting the economic efficiencies. In addition, the growth in online retail in recent years has added to the demand of good delivery to individual consumers and homes.

\section{Intelligent Transportation System technologies}

Technology has been applied to managing motorways and traffic for several decades. In the U.S., cities like Detroit, Michigan, Los Angeles, California, and Houston, Texas were installing early traffic management systems in the late 1960's. Historically, these systems have consisted of the following components:

- Surveillance - use of closed-circuit television (CCTV) or digital cameras to monitor motorways, freeways, and streets.

- Detection - sensor technologies such as inductive loops, radar, or machine vision used to count vehicles, measure speed, measure traffic density, and estimate travel time. In addition, transit vehicles may have sensors that detect and count passengers boarding buses or rail cars.

- Control Devices - field devices used to control traffic such as traffic signals or ramp meters (active control) and dynamic message signs (passive control). 
- Telecommunications - a combination of wired and wireless communication to connect field devices with central management or control systems.

- Management Software - a single software application or suite of software packages that manages field devices, collects and stores data, displays data to traffic operators, and performs some level of data analytics.

Much of this ITS technology can be considered part of the existing roadway infrastructure. In urban centres of many countries, the ITS infrastructure covers a large geographic area supporting wide-area transportation management and traveler information. In addition to overall transportation system management, the information from these ITS deployments can be used for safety and mobility applications to improve CMV safety, efficiency, and mobility.

\section{ITS applications to assist commercial motor vehicle safety and mobility}

The existing ITS infrastructure in many urban areas can generate data that can be shared with freight companies, logistics companies, and individual truck drivers to improve CMV safety, efficiency, and mobility today.

\section{Use of real-time data for freight optimisation}

With the importance of freight on-time delivery, real-time data from ITS can allow freight and logistics companies to better optimize their truck operations and routes to deliver goods. The U.S. DOT Freight Advanced Traveler Information System (FRATIS) program has focused enhancing traveler information systems to address freight needs by integrating modal facility wait times, roadway incidents, work zones, road closures, and truck routing restrictions (FHWA, 2012). The potential benefits of additional real-time data is improved truck fleet efficiency and productivity, better decision making by freight dispatchers, improved routing to destinations.

One specific application of FRATIS is drayage optimization. The freight drayage optimization application optimizes truck and load movements between freight facilities, while balancing for early and late arrivals. Greater efficiencies can be gained by assigning trucks with time windows for pick-up and drop-off. This application would allow drayage operations to be more efficient with less trucks by proving drayage truck load matching and container availability at land and water ports.

Another application of FRATIS is long-distance route optimization. ITS along major interstate routes allows for the continuous monitoring of roadway conditions. Delays, construction, and incidents can be monitored and used in determining the best routes. The I-95 Corridor Coalition is one of the best examples in the U.S., as shown in Figure 3 (I-95, 2017). 
Figure 3. I-95 Corridor

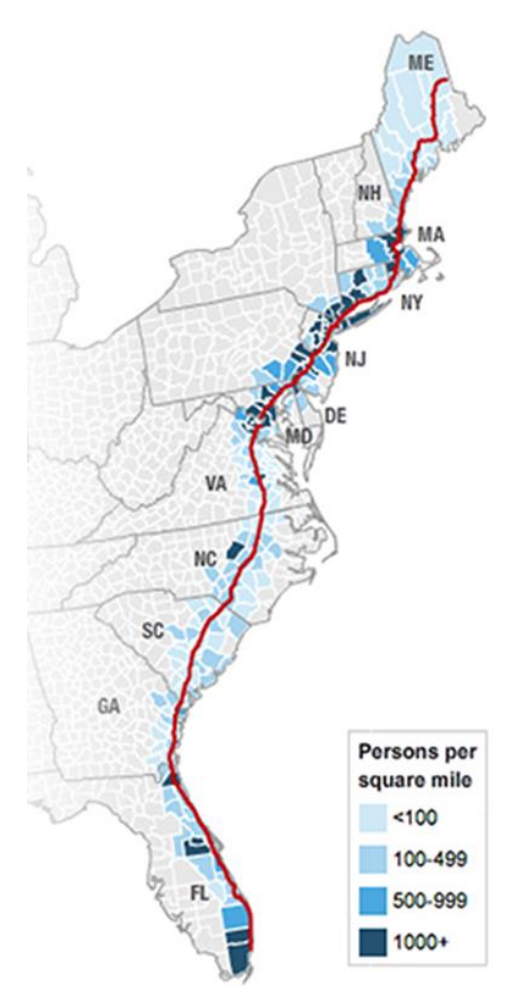

Source: I-95 Corridor Coalition (2017).

\section{Corridor management}

One of the trends in corridor management has been the holistic management of the transportation corridor. Termed Integrated Corridor Management (ICM) in the U.S. (often called managed motorways in Europe), the idea is to improve mobility and reduce congestion by managing all modes and all transportation networks in a corridor, regardless of geographic boundary or agency jurisdiction. The data across modes and routes must be analysed and made available to travelers in the corridor to allow them to make the best travel mode, route, and time decisions. The transportation operating agencies make control strategy decisions (i.e., changing traffic signal timing or ramp metering rates, recommending alternate routes or modes) to optimise the network and possibly share the recommend strategy with travelers.

The U.S. DOT has spent the last decade planning, researching, and demonstrating the ICM concept in the U.S. The U.S. DOT designated eight cities as ICM Pioneer Sites. From these eight cities, two cities, Dallas, Texas and San Diego, California, were granted funding to deploy and operate an ICM demonstration (FHWA, 2012), an shown in Figure 4. These sites projected to generate savings in travel time, fuel, and emissions by optimizing the corridors and proving better traveler information on corridor travel options (ITS-JPO, 2014). The freight industry can benefit from some of the ICM corridor management strategies. Trucks are able to take advantage of real-time traffic information from ICM systems to avoid congestion and use alternate roadways. One of the greatest benefits to freight stakeholders is improved situational awareness of conditions in the corridor. Freight companies have little information on work zones and congestion strategies being deployed and rely on information from media, dispatch, and other drivers (FHWA, 2015). 
Figure 4. I-15 San Diego ICM and U.S. Dallas ICM corridors
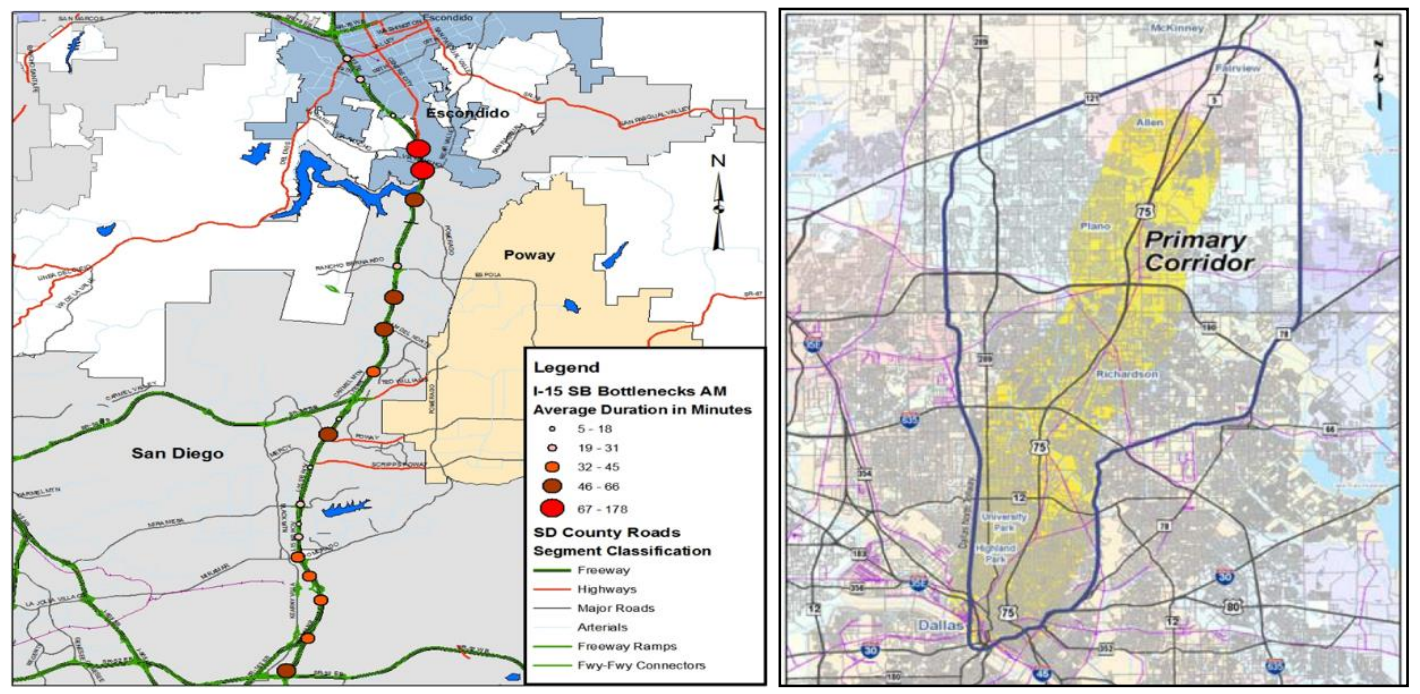

Source: San Diego Association of Governments and Texas A\&M Transportation Institute.

An example of a simple application of corridor management with real-time traffic data on two major routes in a corridor is near Austin, Texas, USA. The Texas Department of Transportation monitors I-35 and the parallel route of SH-130 in real-time, including delays due to construction, incidents, or recurring congestion. The real-time travel time is presented on highway guide signs that are a hybrid static sign with dynamic travel-time inserts to display the minutes to the travel to a primary destination. As shown in Figure 5, there are two junctions southbound (noted by an " $A$ ") where the real-time travel information is displayed for both I-35 and the parallel route of SH-130. The SH-130 route is a tolled facility, passenger and truck drivers alike have to weigh the travel time advantage with the toll cost in making their decision to divert to the SH-130 alternate route. In the northbound direction, there is a junction (marked by a "B") where real-time traveler information is again displayed for the two routes.

\section{Figure 5. Dynamic corridor travel time on I-35 near Austin, Texas, USA}

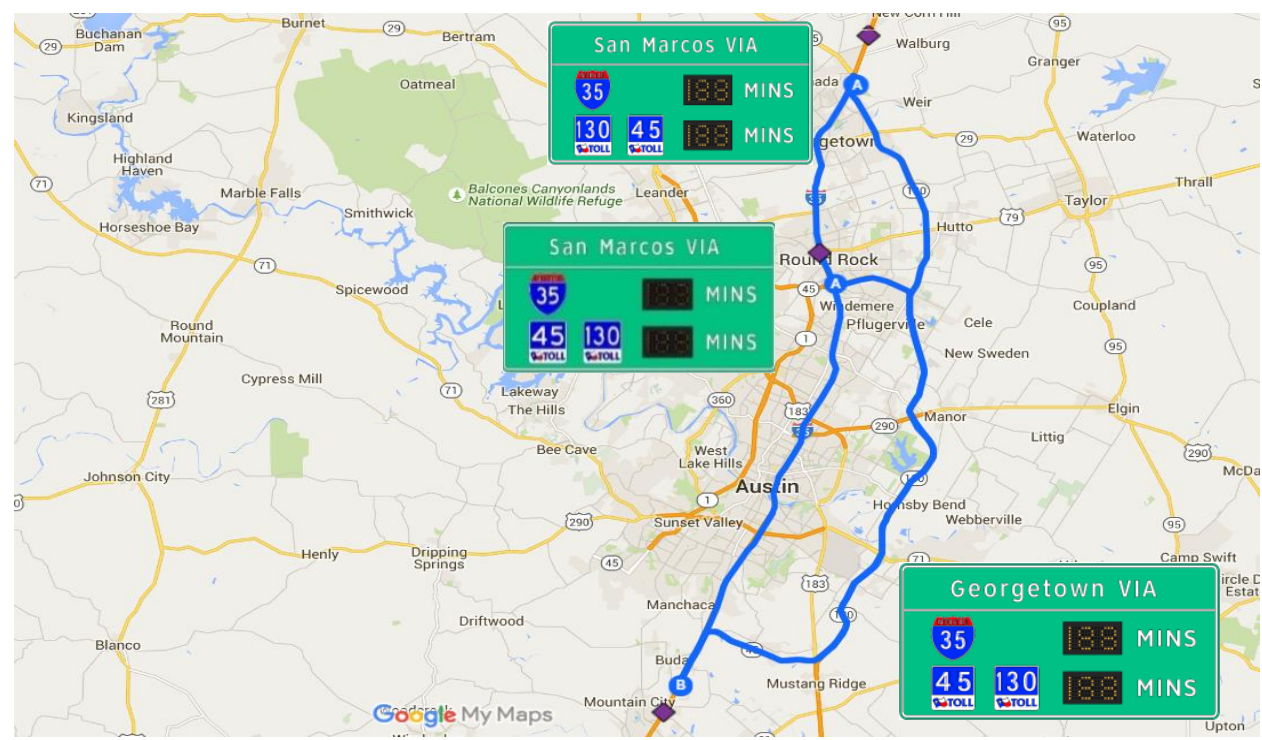

Source: Texas A\&M Transportation Institute (TTI). 
A challenge of these corridor management strategies is getting traveler information to the driver enroute. Advanced technologies on CMVs offer an additional avenue to present corridor information to truck drivers in real-time to avoid congestion and optimize freight efficiency.

\section{Signal priority to assist commercial motor vehicle movements}

Traffic signals allocate right-of-way by providing green time to different traffic movements at an intersection. Because of the size and weight of trucks, their acceleration and deceleration performance differs from passenger cars. Traffic signal operation can be improved by not stopping a truck approaching an intersection. If the truck is stopped on an approach, especially if it is the first vehicle in the queue, it can add to the delay starting up on green for that approach. Additionally, breaking trucks approaching an intersection can put additional wear on the pavement (Sunkari, 2000).

To reduce truck stops at signalized intersections, sensors must be able to detect trucks in sufficient time to adjust the traffic signal timing. An example of a system installed in Texas is shown in Figure 6. In this application inductive loops on the approach are used in conjunction with a classifier to detect trucks. The vehicle classification and the speed of the vehicle are communicated in real-time to the algorithm running on the field computer. The algorithm obtains the signal status information from the back panel of the signal controller cabinet via the digital I/O board. Based on the signal status and the speed of the truck, the algorithm determines if a hold call to extend the green time needs to be placed. If a truck arrives during the red indication, no hold call will be placed. A call for hold will be placed if a truck arrives during the green indication. The duration of hold will depend on the truck speed (Sunkari, 2000).

Figure 6. Truck signal priority system
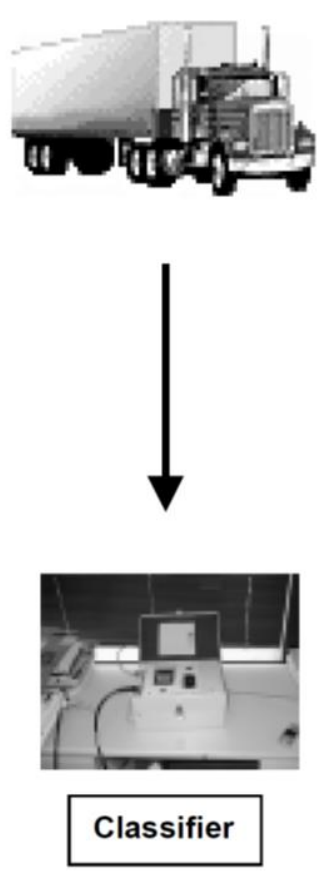
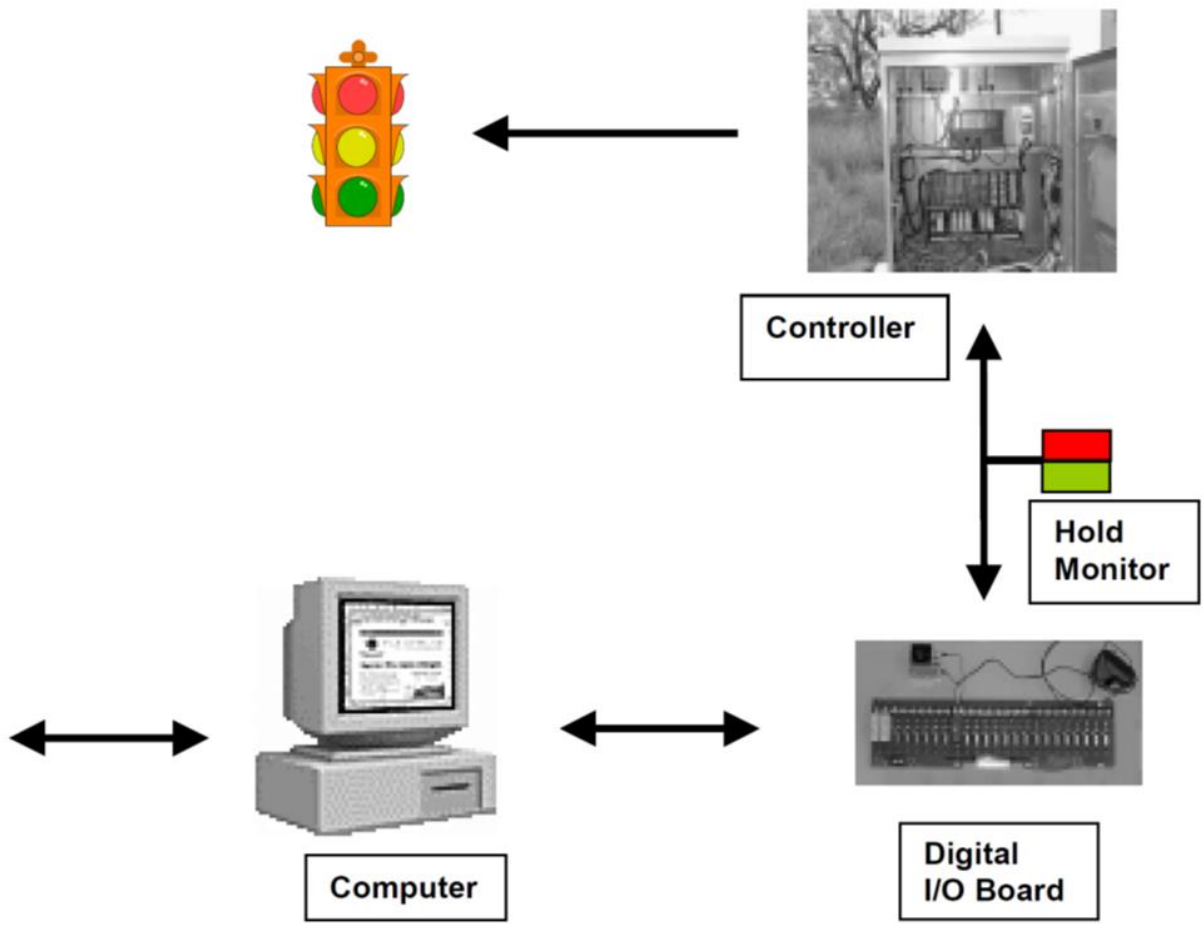

Digital I/O Board

Source: Texas A\&M Transportation Institute (TTI). 
There are alternate sensors on the market to detect trucks and wireless communication solutions that can reduce the need for wired communication infrastructure back to a suitable location to detect the truck on the approach. For high-speed environments, this may be advantageous.

\section{Commercial motor vehicle safety applications}

ITS technologies also offer applications to improve safety for CMVs. Many of these applications revolve around trying to communicate information about the condition of the infrastructure to the truck driver.

\section{Curve speed warnings}

The ability of a truck to navigate a roadway horizontal curve is dependent on several factors. The roadway infrastructure design elements of deceleration length before the curve, roadway cross slope, curve superelevation (before and in the curve), and pavement condition are important. The truck's centre of gravity, load weight, suspension, and tires are also factors. Because of the variability across all these variables and the crash experience on roadway curves (especially on direct connections between roadways), transportation agencies have installed additional technologies to warn truck drivers.

Dynamic curve warning systems use radar to measure the speed of vehicles approaching a curve, display the speed at which the curve can be safely negotiated on electronic signs, and warn drivers to slow down based on real-world conditions. These systems rely on the truck driver to see dynamic warning signs and devices in sufficient time to take corrective action.

\section{Road weather management}

Weather affects both the driver and vehicles performance. Visibility impairments, precipitation, high winds, and temperature extremes can affect the driver's performance. The vehicle performance (i.e., traction, stability and maneuverability) can also be affected by these weather conditions. Poor driver and vehicle performance can subsequently impact crashes, traffic flow, and agency and freight productivity. Road weather sensors, especially in regions that regularly experience winter weather events, are installed as part of the roadway infrastructure. Road weather sensors can deliver information to travelers in real-time about icy bridges, water on the road, rain or fog ahead, and other potentially hazardous conditions through traveler information systems. Both passenger and truck drivers can use this information for safer vehicle operation.

These real-time road conditions can also be used by transportation agencies in treating and maintaining the roads. Decision support systems that use the road weather data can predict how conditions will change and schedule road weather management strategies to make the best use of resources, including staff, vehicles, and treatment product.

\section{Smart work zones / End of queue warning systems}

Dynamic message signs, as part of an ITS, allow transportation agencies to warn travelers about work zones and lane closures. Traveler information can be presented in advance of temporary closures to allow travelers to plan their travel accordingly, or the information can be presented in real-time to warn drivers of an approaching work zone.

Smart work zones build on the work zone alerting system and incorporate real-time data on the traffic conditions near lane closures. Traffic queues can build upstream of a lane closure and form an unexpected condition. One of the goals of a smart work zone is to warn passenger and truck drivers of the presence and distance to a traffic queue. As shown in Figure 7, additional sensors are placed near the 
lane closure to monitor speeds upstream of the lane closure. Then, dynamic signs can be used to warn of slow and stopped traffic ahead and provide the approximate distance to the end of the traffic queue.

\section{Figure 7. Work zone queue warning system}

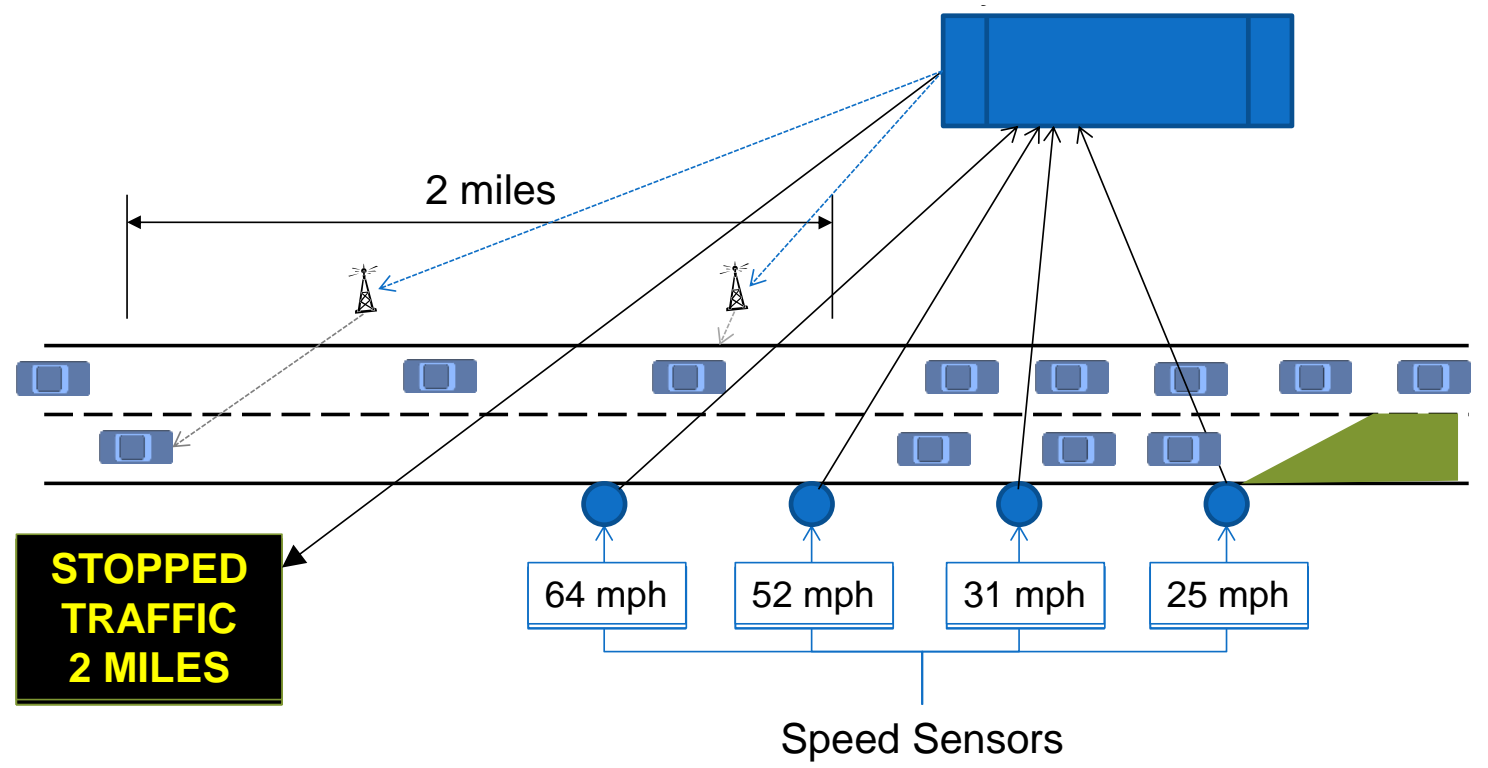

Source: Texas A\&M Transportation Institute (TTI).

\section{State-of-the-industry and ITS infrastructure}

An issue facing the transportation community is the support for operation and maintenance of ITS infrastructure. Many agencies struggle to secure the on-going funding necessary to operate and maintain field devices, upgrade software, and support recurring telecommunication costs. It is often easier to find the capital funding to build the ITS infrastructure than it is to pay for the operation and management. State agencies have expressed that it is easier to get funding for high-visibility construction projects than for ITS projects (RITA, 2013). If ITS infrastructure is important to the next generation of transportation technologies, funding financing solutions will be needed to maintain the ITS infrastructure capable of generating data and information from smart infrastructure.

However, ITS solutions have expanded and integrated across modes and jurisdictions. The increased use of ITS opens up new business models to support the operations and maintenance costs. Transportation providers will need to look at public-public and public-private partnerships to support the on-going costs ITS infrastructure. 


\section{Connected vehicle (CV) technologies}

The advancement of sensor and telecommunication technologies has moved the next generation of transportation toward connected vehicles. Vehicle connectivity holds the promise to reduce crashes and improve efficiency in navigating the transportation network.

\section{Definition of connectivity}

Connectivity related to CVs can be accomplished by various wireless telecommunications means. Some examples are cellular, Wi-Fi, and dedicated short range communication (DSRC). Many original equipment manufacturers (OEMs) have connectivity to their cars to transmit data back and communicate with their customers. Furthermore, there is connectivity between vehicles, termed vehicle-to-vehicle (V2V) communication, connectivity between vehicles and infrastructure, termed vehicle-to-infrastructure (V2I), and connectivity to other uses (i.e. bicycles, pedestrians) and other devices (e.g., smartphones), termed vehicle-to-everything (V2X).

\section{DSRC 5.9 GHz communication}

In the U.S., the Federal Communications Commission (FCC) allocated $75 \mathrm{MHz}$ of spectrum in the $5.9 \mathrm{GHz}$ band for use by CV safety and mobility applications. The U.S. DOT has sponsored research, development, and pilot deployment of DSRC $5.9 \mathrm{GHz}$ communication to accomplish V2V and V2I applications. DSRC is a two-way short- to- medium-range wireless communications (i.e., 300 metres) capability that permits very high data transmission (at least 10 times per second) critical in communications-based active safety applications.

\section{Status of U.S. DOT/NHTSA proposed rule making}

In February 2014, the U.S. DOT announced its work on V2V. In December 2016, the U.S. DOT issued a notice of a proposed rule that would advance the deployment of connected vehicle technologies in the U.S. The public comment period for this notice of proposed rulemaking ends in April 2017.

\section{Alternate communications technologies}

Countries in Europe and Asia are exploring other telecommunication technologies outside of DSRC. Europe is testing $4 \mathrm{G}$ LTE and $5 \mathrm{G}$ technologies.

\section{Commercial motor vehicle V2V applications}

CMVs utilizing on-board units with DSRC can take advantage of many of the V2V applications being pursued by the U.S. DOT. These applications focus on preventing vehicle collision operating on high-speed controlled access facilities and arterials with intersections.

- blind spot warning + lane change warning

- control loss warning

- do not pass warning

- emergency electronic brake light

- emergency vehicle alert

- forward collision warning

- intersection movement assist 
- motorcycle approaching indication international icon

- pre-crash actions

- situational awareness

- slow vehicle warning international icon

- stationary vehicle warning international icon

- tailgating advisory

- vehicle emergency response

\section{Commercial motor vehicle V2I applications}

The following V2I applications require status of the infrastructure or location data from the infrastructure to warn drivers. CMVs

- curve speed warning

- in-vehicle signage

- oversize vehicle warning

- pedestrian in signalised crosswalk warning

- railroad crossing violation warning

- red light violation warning

- reduced speed zone warning / lane closure

- restricted lane warnings

- $\quad$ spot weather impact warning

- stop sign gap assist

- stop sign violation warning

- warnings about hazards in a work zone

- warnings about upcoming work zone

The European Commission has started a strategy for Cooperative Intelligent Transport Systems (CITS) to allow road users and traffic managers to share and use new information to coordinate their actions. The cooperative element, enabled by vehicle connectivity, is expected to significantly improve safety, traffic efficiency, and user driving comfort (EC, 2016). The strategy is promoting many C-ITS services that could be available by 2019. Similar to the U.S., the EC has identified early C-ITS services they hope to deploy in the next five years (Day 1 - before 2019, and Day 1.5 after 2019). As shown in Table 1, those early services and their relationship with the infrastructure can benefit CMV operations and safety. 
Table 1. C-ITS services and infrastructure needs

\begin{tabular}{|l|l|}
\hline C-ITS service & Infrastructure component \\
\hline Road works warning & Location of work zones and lane closures \\
\hline Weather conditions & Road weather and pavement conditions \\
\hline In-vehicle signage & Static guide and warning sign information \\
\hline In-vehicle speed limits & $\begin{array}{l}\text { Static regulatory sign information or geo-coding } \\
\text { of speed limits }\end{array}$ \\
\hline Signal violation & Traffic signal status and intersection geometry \\
\hline Signal priority & Traffic signal status and intersection geometry \\
\hline Green light optimal speed advisory & Traffic signal status and regulatory speed limits \\
\hline Shockwave damping & Corridor capacity and regulatory speed limits \\
\hline Information on fueling and charging stations & Location and status of stations \\
\hline On street parking management and information & Location and availability of parking spaces \\
\hline Off street parking information & Location and availability of parking spaces \\
\hline Park and ride information & Location and availability of parking spaces \\
\hline $\begin{array}{l}\text { Connected/cooperative navigation (first and last } \\
\text { mile, route advice, coordinated traffic lights) }\end{array}$ & $\begin{array}{l}\text { Lane closures, incidents, traffic signal status, } \\
\text { vehicle restrictions }\end{array}$ \\
\hline Traffic information and smart routing & $\begin{array}{l}\text { Lane closures, incidents, and traffic signal status, } \\
\text { vehicle restrictions }\end{array}$ \\
\hline
\end{tabular}

\section{Infrastructure applications to support commercial motor vehicle safety and mobility}

CMVs have unique vehicle characteristics in terms of height, width, length, and weight that create challenges in navigating roadways. The market penetration rate of on-board safety system, such as lane departure warning systems, electronic stability control system, and forward collision warning systems, but expected to increase (ITS America, 2014). With these greater adoption of on-board systems, CMVs will be able to benefit from V2I applications being developed for all vehicles.

\section{Geometrics}

In geometric roadway design, there assumptions about the driver and vehicles. And often, some representative performance threshold (i.e., $95^{\text {th }}$ percentile driver, worn tires) are used to calculate the minimum values for geometric design elements. CV allow specific information about a driver and a vehicle to be considered in conjunction with the roadway geometric design values. 


\section{Horizontal alinement}

The curve warning application discussed previously makes assumptions about trucks operating on the roadway. If a truck approaching a curve is exceeding the safety operating speed based on those assumption, the driver will be alerted. Often that alert is given by roadside dynamic message signs. With $\mathrm{CV}$ technologies and greater on-board capability, the curve warning application can utilise the trucks own information on that truck's characteristics and load with the roadway geometrics to generate truckspecific warnings.

The other challenge for CMVs can be the changes in cross section. In physically constrained areas or during work zones, lane widths and shoulder widths may be reduced. Warnings to increase truck driver attention to these situations can aid in safe operations in these constrained cross sections.

\section{Vertical alinement}

The U.S. DOT's Connected Vehicle Reference Implementation Architecture (CVRIA) contains descriptions of all the CV applications. The Oversize Vehicle Warning (OVW) application is defined in the CVRIA as follows:

OVW uses external measurements taken by the roadside infrastructure, and transmitted to the vehicle, to support in-vehicle determination of whether an alert/warning is necessary. Specifically, the infrastructure data equipment detects and measures the approaching vehicle's height and width. The infrastructure component of the application transmits the vehicle measurements, along with bridge, overpass, or tunnel geometry, to the OVW vehicle application. The vehicle application utilizes these data to determine whether the vehicle can clear the bridge or tunnel. If deemed necessary, the driver is alerted to the impending low height and/or narrow horizontal clearance bridge or tunnel prior to a decision point, enabling the vehicle to reroute and avoid a collision. If the vehicle driver ignores the alert and continues along the route, the vehicle will generate a warning indicating an impending collision at a point near the bridge or tunnel approach. To support unequipped vehicles the infrastructure will display warning or reroute information when the measurements indicate that a vehicle does not have adequate height or width clearance. This application could be expanded to consider overweight as well as height and width. (CVRIA, 2016)

Unlike passenger cars, CMVs have to be aware of low clearances under overpasses, bridges, and tunnels. With CV technologies and on-board systems, the information can be communicated to truck drivers well in advance of problem locations. Furthermore, the warnings can be tailored to the trucks exact height and load height. This becomes increasingly important in real-time truck route optimization that might re-route a truck onto secondary roadways with lower vertical clearance practices.

\section{Cross section}

One roadway cross section issue for CMV is the shared space in urban areas with other uses. Conway (Conway, 2016) researched the overlap between bike routes and bus routes in New York City. The study found that 89 miles overlapped the city's local truck network, representing $15 \%$ of the bicycle network and $11 \%$ of the truck network. The separation of bike lanes on these truck routes causes challenges for CMV to navigate these routes with pavement markings and physical barriers and curbs.

\section{Interchanges, access, merging, diverging and weaving}

$\mathrm{CV}$ technologies can assist CMVs in navigating interchanges and the associated merge, diverge, and weaving areas near interchanges. One challenge in navigating interchanges, especially in high-traffic urban environments, is following the correct lane at interchanges with left-hand exits, multi-lane exits, 
lane drops, and lane additions. During congested time, CMVs need to know which lane to occupy in advance of traffic queues that may form before the interchange.

In rural environments, trucks often travel in the outside lane (i.e., slow lane) of a controlled-access facility. When disabled vehicles are on the shoulder of these facilities, it is common practice for truck drivers to move over to give the disabled vehicle more space. CV technologies can allow surrounding vehicles to be aware of such lane changes.

Merging traffic can also be a challenge on rural freeways and motorways. Trucks will frequently change lanes to allow for entering traffic onto the roadway. CV technologies, and some on-board analytics, would allow vehicles to exchange information about travel speed and acceleration to make those merges safer and potential reduce the amount of lane changing required.

\section{Intersections and traffic signal systems}

Intersection collisions account for approximately one-third of all crashes in the U.S. There have been some intersection collision avoidance systems utilizing more traditional ITS technologies. These systems use sensors to monitor traffic approaching intersections and warn vehicles of approaching cross traffic via roadside signs. Test deployments have indicated that these systems are effective in both reducing the speed of approaching vehicles and reducing the number of collisions at high-accident intersections.

CMV on-board safety systems have the potential to reduce turning collisions at intersections. The technologies can identify roadside obstacles, such as trees and traffic control devices, and warn the driver of the possibility of collision. These same safety systems can detect vehicles operating near and around trucks turning at intersections. Light-duty vehicles conflicting with the turning path of the CMV can be detected and the CMV operator warned of the potential conflict.

V2V applications utilizing DSRC have the further potential to prevent two vehicles from crashing into each other. The early V2V applications of interest to U.S. DOT at signalised intersections is red light violation warning. Another high priority V2X application at signalized intersections is pedestrian in the crosswalk warning. With greater penetration of CV technologies across the vehicle fleet, intersection collision avoidance applications will gain greater impact. Collision avoidance systems have applications at both signalised and unsignalised locations.

The U.S. DOT is also working on unsignalised intersection applications. Two high priority applications are: Stop Sign Gap Assist and Stop Sign Violation Warning. These use CV technologies to monitor the gaps for a stopped vehicle on the cross street and warn of potential stop sign violations.

Another type of intersection is a highway-rail intersection (HRI). CV technologies allow for railroad crossing violation warnings. In the future, $\mathrm{V} 2 \mathrm{~V}$ communication could support warnings between vehicles and trains if trains are equipped with DSRC on-board units. This may be important to the CMV industry as trucks have longer acceleration and deceleration needs as they approach HRIs.

Another issue at intersections is the wear on pavement that heavy vehicles can cause with repeated stopping at stop and signal controlled intersection approaches. Smarter traffic signal priority with heavy vehicles communicating to intersections can reduce the stops and accelerations of trucks stopped at traffic signals. Better connectivity between CMVs and intersections could provide greater advanced notice of traffic signal status; thus reducing the hard braking and wear on the roadway pavement.

\section{Unplanned events / incidents}

Incident are the most common unplanned event. Transportation agencies use ITS technologies to detection, monitor, and warn travellers of incidents on roadways from traffic management centers 
(TMCs). The TMCs are part of the ITS infrastructure that could aid with dissemination of information to CMVs. With deployment of CV technologies, incidents can be communicated directly from the roadside or other vehicles at the incident location to CMVs in advance to take proper action or potentially re-route around incident locations to find quicker alternate routes.

\section{Planned events / work zones}

Work zones or planned lane closures can be aided by CV technologies. U.S. DOT and Texas Department of Transportation are working on a Connected Work Zone project. The first phase of this project is to communicate location, lane closure, delay, and traffic queue information to CMVs. This would initially be accomplished using cellular communication to on-board units in the truck. The second phase migrates this same information to trucks and passenger cars using $\mathrm{CV}$ infrastructure. Using $\mathrm{CV}$ technologies allows to overcome the issue of relying on roadside dynamic message signs to communicate work zone information. The CV technologies would allow to communicate more information further in advance to allow the drive to take proper action and potentially re-route around the work zone and construction location.

\section{Use of automation on motorways}

Heavy-duty and light-duty vehicle OEMs have been installing more safety system on vehicles. The sensors and computing power of these systems have evolved to where parts of the driving task can be partially or fully automated. To explain what is meant by automation, the Society of Automotive Engineers (SAE) have defined six levels of automation, which has since been adopted by the U.S. DOT (U.S. DOT, 2016), and is shown in Table 2.

The technologies that have enabled the advancement of vehicle automation are: radar, LIDAR, video camera systems, DSRC, 4G/5G Long-Term Evolution (LTE) wireless communications, and differential global positions system (DFPS). The integration of these technologies have allowed freight companies to demonstration truck automation in the U.S. 
Table 2. SAE/U.S. DOT levels of automation

\begin{tabular}{|l|l||}
\hline SAE Level & Description of automation \\
\hline \hline Level 0 & The human driver does everything. \\
\hline Level 1 & $\begin{array}{l}\text { An automated system on the vehicle can sometimes assist the human driver } \\
\text { conduct some parts of the driving task. }\end{array}$ \\
\hline Level 2 & $\begin{array}{l}\text { An automated system on the vehicle can actually conduct some parts of the } \\
\text { driving task, while the human continues to monitor the driving environment } \\
\text { and performs the rest of the driving task. }\end{array}$ \\
\hline Level 3 & $\begin{array}{l}\text { An automated system can both actually conduct some parts of the driving task } \\
\text { and monitor the driving environment in some instances, but the human driver } \\
\text { must be ready to take back control when the automated system requests. }\end{array}$ \\
\hline Level 4 & $\begin{array}{l}\text { An automated system can conduct the driving task and monitor the driving } \\
\text { environment, and the human need not take back control, but the automated } \\
\text { system can operate only in certain environments and under certain conditions. }\end{array}$ \\
\hline Level 5 & $\begin{array}{l}\text { The automated system can perform all driving tasks, under all conditions that } \\
\text { a human driver could perform them. }\end{array}$ \\
\hline \hline
\end{tabular}

Source: "Federal Automated Vehicle Policy, Accelerating the Next Revolution in Roadway Safety," NHTSA, U.S. Department of Transportation (U.S. DOT, 2016).

\section{Recent industry developments}

CMVs under various levels of automation are being tested on freeways and motorways. In the U.S., FreightLiner and Otto (now part of Uber) have done demonstrations in Nevada, and Otto performed another recent demonstration with an automated truck in Colorado (Short, 2016).

The U.S. DOT/NHTSA recently released guidance on automated vehicles (U.S. DOT, 2016). In that document, NHTSA provides a 15-point safety assessment of best practices "for all individuals and companies manufacturing, designing, testing, and/or planning to sell automated vehicle systems in the United States." Rather than creating legally-binding regulations or minimum levels of safety the vehicle industry must meet, the agency promulgated a voluntary self-assessment and stated that some elements may become "mandatory and binding through future regulatory actions." This advance guidance provides stability and predictability to the industry. This guidance applies to all forms of AVs (conditional- and highly-automated), including test and commercially-ready vehicles, and NHTSA encourages developers to apply for regulatory exemptions if the vehicles push the boundaries of conventional vehicle design.

While regulatory progress has been slow, there are signs that the European Union is working to advance AV development. In April 2016, all 28 EU member states signed The Declaration of Amsterdam, which established "the steps necessary for the development of self-driving technology in the EU. In this document, the Netherlands, the European Commission, EU member states and the transport industry pledge to draw up rules and regulations that will allow autonomous vehicles to be used on the roads" (EU, 2016). The declaration indicates the signatories' intent to advance automation through a variety of actions and venues, like sharing best practices across countries and companies, developing standards for inter-vehicular communications and security, and working with national and international bodies to update regulatory policy. 


\section{Role of infrastructure in automation}

AV technologies perform best on high-quality infrastructure and roadways (Short, 2016). High visibility lane striping, well maintained pavement markings, highly reflective signage, well maintained traffic control devices all aid in the operation of AVs.

Automation control systems have challenges when unexpected events occur. Examples of these types of unexpected events include work zones, roadway incidents, and changes in pavement condition. $\mathrm{AV}$ technologies also have difficulty with the variation with infrastructure condition. Over time, the sign materials, lane stripes, and pavement markings can fade, degrade, or be removed. Through connected automation, the AV technologies can be enhanced by the infrastructure data and information that can be transmitted through connectivity.

\section{Digital infrastructure}

Digital infrastructure can be defined as the static and dynamic digital representation of the physical world (Flament, 2014). AV technologies will need or benefit from digital infrastructure. To create a digital infrastructure, cooperation is needed from the vehicles and the infrastructure operators to collect, update, and correct changes in the physical infrastructure. In the European Union, it has been proposed that a framework be established with a governance over the data sourcing, processing, sharing, and maintaining. Harmonized interfaces and common resources will be needed to collect and maintain the digital infrastructure (Flament, 2014). In the U.S., similar efforts are being made in collecting digital infrastructure for use in safety and mobility applications.

\section{Mixed traffic versus exclusive facilities for automation on motorways}

Kaplan (2016) makes the argument that the benefits of the automobile were not realized until the infrastructure was improved and other users (pedestrian and horse-drawn carts) were removed from the roadway. He argues in his report that the same delay in benefits may result for AVs. To realize the full potential of AVs, the human-driven vehicles must be separated from AVs and the infrastructure must be improved (i.e., connectivity).

Some state agencies and toll authorities in the U.S. are looking at their controlled-access facilities as early locations for deployment of automation. In the U.S., several cities have extensive barrier separated high-occupancy vehicle (HOV) lanes or managed lanes. Because these facilities are managed, the public agencies have greater control over the user requirements to access the lanes and can focus resources on maintaining the infrastructure. Signing, pavement marking, and lane lines can be kept at the necessary levels to optimize the automation during these early pilot demonstration. The infrastructure care may even be higher than infrastructure on general purpose facilities to demonstrate the effectiveness. Some of these facilities may offer potential for CMVs with automation to operate, with mixed traffic or as CMVonly facilities during certain times of the day. 


\section{New opportunities with transformational technologies}

ITS, CV, and AV technologies have the potential to create new opportunities for CMV operations. A few of these applications are truck platooning, truck parking, and last-mile freight delivery.

\section{Platooning in both rural and urban environments}

Truck platooning has been demonstrated in Europe, Asia, and the U.S. Much of these demonstrations have been on controlled access facilities. One of the early demonstrations in Europe was the SARTRE project. The SARTRE project demonstrated 5 vehicle platoons with mixed traffic (i.e., cars and trucks). The platoons consisted of a lead vehicle driven manually and one or more following vehicles instrumented with automated control of both longitudinal control (acceleration, deceleration, and gap maintenance) and steering control (Chan, 2012). The demonstration showed that these technologies are close to production ready and can handle a number of real world scenarios on conventional motorways. One SARTRE report identified two infrastructure elements that may need more attention. First, design of roadside barriers may need to consider the impact of a platoon running off the road where multiple vehicles could strike a barrier in a short time frame (Davila, 2012). Second, the design of toll plazas on the motorways may need to be addressed to provide consistency on all tolled motorways. The platoons may be impacted by the narrow lane widths through toll plazas (Davila, 2012).

In the U.S., the University of Auburn led a research project on driver assistive truck platooning (DATP) with an industry team of partners including Peloton Technology, Peterbilt Trucks, Meritor WABCO, and the ATRI. The project included radar for longitudinal sensing, DSRC-based V2V communication, satellite positioning, and a human-machine interface (Bevly, 2015). This was considered a Level 1 Automation project as only the longitudinal control was automated. The project showed that the DATP appeared suitable for truck-load and less-than-truck load operators and produced aerodynamic benefits for distances up to 100 feet separation between trucks (Bevly, 2015).

In urban areas, the physical infrastructure may present more challenges. Jassen et al. (2015) point out that roundabouts, bridges, and access ramps could be constraints for truck platooning. This is where V2I communication to the infrastructure to communicate geometric changes, interchange and ramp locations, and work zone locations could assist with truck platooning.

\section{Truck parking}

One key infrastructure component impacting truck efficiency and safety is truck parking. Truck drivers must rest for 10 hours between on-duty periods and rely on public and private parking facilities to take these rest periods (Short, 2016). Thus, knowing the location and availability of truck parking is important.

ITS and CV technologies can bring together this information and communicate it effectively to truck drivers. Smart parking systems that use ITS technologies, while mature, have not been widely deployed in truck parking area along roadways. In addition, there are considerable private facilities along these same roadways. Michigan Department of Transportation deployed one of the more comprehensive truck parking information and management system along I-94 in Michigan (MDOT, 2014). The goal of the project was to identify available parking in the corridor and share that information with CMV operators. The project monitored public parking areas and relied on data from private companies on the status of their parking areas. 
ATRI identified parking as one if its top 10 issues affecting the trucking industry and examined the impact of automation (Short, 2016). The report maintained that parking will still be needed even if hours of service can be extended by automation. CMV operators will still need services provided at truck stops such as fuel, food, and emergency maintenance facilities. The report speculated that level 3 automation may allow drivers to engage with on-board devices that may allow a driver to be more efficient by using dynamic routing and identifying parking areas. Under level 4 automation, the number of stops may decrease if hours of service are lengthened, which may reduce some of the parking demand and make added parking capacity available. The report further speculated that level 5 automation may eliminate hours of service regulations and result in even fewer needed stops.

\section{Accommodation of deliveries and last-mile freight movements}

Last mile freight movements deal with the last leg of the supply chain between a distribution centre and the customer. In the last five years, alternate modes encouraged by technology development have emerged. Some examples are:

- Human pedal-powered delivery

- Unmanned Aerial Vehicle (UAVs) delivery

- Ground-based robot delivery

- Shared mobility / Transportation Network Company (TNC)

These delivery alternatives use small form factors than trucks to make last-mile deliveries. These have the advantage of greater mobility into denser urban networks closer to the point of delivery. They also make take demand of the roadway network and infrastructure, reducing truck-related congestion. Alternatively, these delivery services may have new requirements on the infrastructure to be most effective.

\section{Assessment of near-term and mid-term developments}

On-board safety systems for CMVs have great potential to improve safety and efficiency in the near term. Advanced driver assistance systems (ADAS) can provide alerts and warning and assist in the CMV operation to reduce crashes and improve efficiency. The additional notification to CMV operators of potential hazards may reduce crashes. Some of these ADAS include:

- adaptive cruise control

- automatic braking

- blind spot detection

- collision avoidance systems

- driver drowsiness detection

- Llane departure warning systems 
Connectivity also holds immediate opportunity to expand traditional ITS solutions for safety and mobility by creating more effective applications that work with CMVs. Connected on-board safety systems offer more effective ways of communicating directly to the CMV operator. Connectivity between CMVs and the infrastructure allows for specifically-tailored applications for every vehicle based on that vehicle's own characteristics as it navigates the transportation infrastructure. CMV fleets may be early adopters to gain the safety and mobility benefits. However, for national CMV companies to invest, such as long-haul trucking companies that operate across the U.S., national guidance and leadership is needed in setting standards to reduce the chance of redundant or non-compatible systems from state to state across the country (RITA, 2013).

\section{Summary and observations}

The light-duty vehicle industry has gained significant attention as connected and automated vehicle technologies are demonstrated and deployed. The heavy vehicle and CMV industry have equal opportunity to demonstrate safety and operational benefits, while initially not garnering the same media attention. Both the U.S. and Europe, are seeing connectivity open up new applications to get greater benefits from the existing ITS deployments and assist with the transformation that automation will bring to transportation. What is needed are evaluations of demonstrations and early deployments to generate data that can be used by the CMV industry to determine the benefits of integrating infrastructure data with CMV on-board safety systems. Both benefits to society and benefits to the CMV industry need to be quantified. The potential for immediate return on investment to the CMV industry (in terms of reduced crashes, reduced fuel consumption, improved operating efficiency) is a reason why transformational transportation technologies, such as connected and automated technologies, have a great potential to have early success. 


\section{References}

American Transportation Research Institute (ATRI) (2013), "2013 Impacts of Congestion on Trucking," ATRI, Arlington, Virginia. ATRI_2013_Trucking_Congestion_Costs.pdf.

Barra, M. (2015) "DAVOS 2016: GM Boss Sees A Revolution in Personal Mobility, Forbes, http://www.forbes.com/sites/joannmuller/2016/01/18/davos-2016-gm-boss-sees-a-revolution-inpersonal-mobility/\#243f9d5375e3, January 2016.

Bevly, D., et al. (2015), "Heavy Truck Cooperative Adaptive Cruise Control: Evaluation, Testing, and Stakeholder Engagement for Near Term Deployment: Phone One Final Report," Auburn University, Auburn Alabama.

Chan, E., P. Gilhead, P. Jelinke, P. Krejci and T. Robinson (2012), "Cooperative Control of SARTRE Automated Platoon Vehicles," $19^{\text {th }}$ ITS World Congress, Vienna, Austria, October.

Connected Vehicle Reference Implementation Architecture (CVRIA) (n.d.), U.S. Department of Transportation, Washington, D.C., http://local.iteris.com/cvria/html/applications/applications.html (accessed December 2016).

Conway, A., N. Tavernier, V. Leal-Tavares, N. Gharamani, L. Chauvet, M. Chui and X. Yeap (2016), "Freight in a Bicycle-Friendly City: Exploratory Analysis with New York City Open Data," Transportation Research Record No. 2547, Transportation Research Board, Washington D.C.

Davila, A. (2012), "Report on Infrastructure and Environnent," Document ID: SARTRE_5_002_PU, Applus+ IDIADA.

European Union (EU) (2106) Presidency. Declaration of Amsterdam. 14 April 2016. https://english.eu2016.nl/documents/publications/2016/04/14/declaration-of-amsterdam (accessed November 2016).

European Union Road Federation (ERF) (n.d.), "2012 European Road Statistics," $11^{\text {th }}$ Edition, Brussels.

Federal Highway Administration (FHWA) (2015), "Integrated Corridor Management and Freight Operations," U.S. Department of Transportation, Washington, D.C.

Federal Highway Administration (FHWA) (2012), "FRATIS Concept of Operations," U.S. Department of Transportation, Washington, D.C.

Federal Motor Carrier Safety Administration (FMCSA) (2016), "2016 Pocket Guide to Large Truck and Bus Statistics,” U.S. Department of Transportation, Washington, D.C.

Flamenet, M. (2014), “iMobility Forum Working Group Automation in Road Transport," SIP-ADUS WS, Tokyo.

I-95 Corridor Coalition (n.d.), "I-95 Facts and Stats." http://i95coalition.org/the-coalition-2/i-95-facts/ (accessed February 2017).

Intelligent Transportation System - Joint Program Office (ITS-JPO) (2014), "Integrated Corridor Management: ITS Benefits, Costs, Lessons Learned: 2014 Update Report,” U.S. Department of Transportation, Washington, D.C.

Intelligent Transportation System - Joint Program Office (ITS-JPO) (2013), "Longitudinal Study of ITS Implementation: Decisions Factors and Effects," U.S. Department of Transportation, Washington, D.C. 
Janssen, R., H. Zwijnenberg, I. Blankers and J. de Krujff (2015), “Truck Platooning Driving the Future of Transportation,” TNO, Repot Number TNO 2014 R11893, Delft.

Kaplan, J. (2016), “Roads that Work for Self-Driving Cars”, Wall Street Journal, New York.

National Freight Advisory Committee (NFAC) (2014), "Recommendations to U.S. DOT for the Development of the National Freight Strategic Plan", U.S. Department of Transportation, Washington, D.C.

NHTSA (2015), "Traffic Safety Fact Sheet: 2013 Data," U.S. Department of Transportation, Washington, D.C.

Short, J. and D. Murray (2016), "Identifying Autonomous Vehicle Technology Impacts on the Trucking Industry, American Transportation Research Institute (ATRI), Arlington, Virginia.

Sunkari, S., H. Charara and T. Urbanik (2000), "Reducing Truck Stops at High-Speed Isolated Traffic Signals," Texas Transportation Institute, College Station, Texas.

U.S. Department of Transportation (2016), "Federal Automated Vehicle Policy, Accelerating the Next Revolution in Roadway Safety," NHTSA, Washington, D.C.

U.S. Department of Transportation (2015), Bureau of Transportation Statistics and Federal Highway Administration, Freight Analysis Framework, version 3.6.

U.S. Department of Transportation (2015), "National Freight Strategic Plan. Draft for Public Comment, Washington, D.C.. https://www.transportation.gov/freight/NFSP.

U.S. Department of Transportation (2015), “Jason's Law Truck Parking Survey Results and Comparative Analysis," Washington, D.C. 
